\title{
Desastres: tecnicismo e sofrimento social
}

\author{
Disasters: technicism and social suffering
}

Norma Felicidade Lopes da Silva Valencio ${ }^{1}$

${ }^{1}$ Departamento de Sociologia, Universidade Federal de São Carlos. Rodovia Washington Luiz $\mathrm{km}$ 235, Monjolinho. 13.565-905 São Carlos SP

Brasil.normaf@terra.com.br
Abstract Adopting a critical perspective of the social sciences, this study initially analyzes some aspects of the technicism of the Brazilian Civil Defense to have it as a benchmark of the usual indifference of its technical and operational personnel to the multidimensional social suffering of the groups affected by disasters. The analytical framework is based on documentary research, especially of official records, and also a review of the literature of the main authors in the field as well as recent studies about the most emblematic recent disasters in Brazil. The conclusion reached is that concern about the multidimensional social suffering of the social groups affected by disasters is absent in the institutional framework.

Key words Disasters, Human rights, Civil Defense, Social suffering
Resumo Desde uma perspectiva crítica das ciências sociais, o estudo analisa preliminarmente aspectos do approach tecnicista de defesa civil no Brasil, para tê-lo como referência para a usual indiferença do meio técnico-operacional quanto ao sofrimento social multidimensional dos grupos afetados nos desastres. O quadro analítico se baseia em pesquisa documental, sobretudo em registros institucionais e em revisão de literatura dos autores de referência no debate, bem como nos estudos mais recentes sobre alguns dos casos mais emblemáticos de desastres recentes no país. Conclui-se que a preocupação com o sofrimento social multidimensional dos grupos sociais afetados nos desastres é ausente no escopo institucional.

Palavras-chave Desastres, Direitos humanos, Defesa civil, Sofrimento social 


\section{Introdução}

No Brasil, os desastres são um problema crônico aos quais as políticas adotadas no âmbito do Sistema Nacional de Proteção e Defesa Civil (SINPDEC) não têm conseguido reduzir. Embora os processos mais estruturais de desigualdade e injustiça social estejam presentes na persistência e disseminação dos desastres pelo país, é possível supor que a forma como essa crise tem sido interpretada institucionalmente, respaldando as práticas de seu meio técnico-operacional com os grupos sociais mais afetados, também contribua para esse problema.

Diante isso, tem-se por objetivo apresentar considerações sociológicas acerca do processo constitutivo da visão institucional autoritária que embasa certas práticas técnicas de defesa civil de cunho desumanizante. Num tópico introdutório, faz-se uma sucinta reflexão acerca das relações das ciências duras com a cultura autoritária e militar no tema dos desastres, de onde emerge a hipervalorização da teoria dos hazards e o tecnicismo e, em contraponto, apresenta-se o olhar sociológico na teoria dos desastres. Com tal pano de fundo, são descritos alguns aspectos do contexto brasileiro de ocorrência de desastres, que se somam a atual cristalização do repertório técnico conceitual e à resistência institucional para descartá-lo. Em seguida, focaliza-se o padrão tecnicista de interação com os grupos sociais afetados nos desastres, tendo como esteio estudos empíricos recentes em sociologia dos desastres. Desde aí, são descritas algumas das mais relevantes formas de materialização da violência que tal tecnicismo engendra e que resulta num sofrimento social multidimensional dos grupos sociais mais afetados nos desastres. Finaliza-se, sinalizando para o advento de uma capacidade de mobilização social no tema dos desastres. Trata-se, assim, da apresentação de um quadro panorâmico em torno da relação entre a instituição de defesa civil e os grupos sociais afetados nos desastres, focalizando especialmente a crise aguda no Brasil, de escassa literatura sociológica. Limitações de espaço inviabilizam aprofundar todos esses aspectos, bem como deter-se sobre casos específicos e sobre os processos estruturais de violência, de vulnerabilização e de desigualdade social. Embora sejam eles aspectos importantes da crise crônica, na qual a crise aguda se situa, fogem ao escopo desse trabalho.

\section{$O$ advento da cultura tecnicista na abordagem de desastres}

Nos estudos sobre desastres, há uma distinção importante entre a teoria dos hazards e a teoria dos desastres. A teoria dos hazards enfatiza uma abordagem geográfica, na qual os mecanismos físicos, a distribuição temporal e espacial e dinâmica de eclosão dos eventos físicos têm maior peso, enquanto a teoria dos desastres, construída desde uma abordagem sociológica, enfatiza as considerações sobre a organização social complexa e o comportamento coletivo. Isto é, considera que "a dimensão social converte-se na pré-condição para que a dimensão natural se torne destrutiva"'.

Um approach determinista se constituiu em torno da teoria dos hazards, tornando-o o paradigma hegemônico, agregando várias áreas das ciências duras. Nele, são valorizados sobremodo os modelos de mensuração quantitativa das probabilidades de ocorrência de eventos perigosos e suas causas, vindo ao encontro dos negócios do setor securitário e de outros setores da economia ${ }^{2}$. No bojo desse approach, desenvolveu-se uma conotação moral depreciativa dos sujeitos com comportamentos tidos como perigosos, no intento de responsabilizá-los por suas perdas e danos e invisibilizar os processos sociais implica$\operatorname{dos}^{3}$. Certas lógicas científicas favorecem a adoção de certos sistemas de crenças e valores e, neste caso, o determinismo contribuiu com o advento do tecnicismo, isto é, possibilitou a imposição de uma racionalidade instrumental que escamoteia as questões éticas e políticas implicadas, e se manifesta como uma "expressão exacerbada de controle, intervenção e produção de materia-

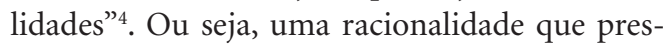
supõe o assentimento a uma relação social entre desiguais, a qual se dá "entre detentores do poder de comando e destinatários do dever de obediências"5. Um paradigma hegemônico se desenvolve como uma relação dominadora, que se apresenta sobre um princípio da disjunção e redução do social ao físico, seduzido pela ideia de modelos abstratos que podem ser aplicados para a interpretação de qualquer realidade socioambiental, e o preço dessa racionalização são as mutilações de entendimento do real e a barbárie ${ }^{6}$.

Apesar disso, na América Latina, os órgãos nacionais de proteção e defesa civil adotaram o enfoque dos hazards e costumam referir-se aos danos e prejuízos coletivos e de grande monta, associados a intensas precipitações pluviométricas, secas, erupções vulcânicas, terremotos e 
afins, como desastres naturais. Na coletânea intitulada Los desastres no son naturales, produzida pela Red de Estudios Sociales em Prevención de Desastres em América Latina - La Red, enfatizase que, quando os planejadores de Estado dizem que os desastres são naturais, buscam evitar um questionamento mais amplo sobre o processo sócio histórico no bojo do qual se desenrola a dinâmica socioespacial. É nesse processo que estão os elementos explicativos de danos e prejuízos a certas comunidades e não a outras (embora expostas a eventos similares), como também as forças que atuam na construção de um repertório discursivo que acusa certas populações de despreparadas, sem consciência, sem percepção de seu mundo. O domínio das ciências duras sobre o tema age como um impedimento para a adoção de uma perspectiva mais ampla de discussão. Lavell ${ }^{7}$, na referida coletânea, enfatiza:

El dominio que ejercen las ciencias naturales y básicas sobre la problemática de los desastres en el subcontinente latinoamericano es casi total. El estudio de patrones sísmicos y climatológicos, de la dinámica terrestre, $y$ de estructuras ingenieriles entre otros variados aspectos, pone un énfasis notorio en los problemas de predicción y en la adecuación de estructuras a los parámetros físicos de los eventos naturales que amenazan la sociedad. Pero la sociedad no aparece en la fórmula, ni como objeto de estudio, ni como objeto de acción y cambio en cuanto sus patrones de comportamiento y de incidencia en la concreción de situaciones de desastre [...] El énfasis puesto en la predicción, prognosis, monitoreo $y$ control estructural con énfasis en eventos de magnitud se encuentra confirmado, en América Latina, por el mismo desarrollo institucional y el acceso a fuentes de financiamiento. Los centros e instituciones dedicados a las geociencias son los que mayor proyección y presencia tienen, en comparación con el casi nulo desarrollo institucional en torno a las ciencias sociales.

Concordando com Lavell, García Acosta ${ }^{8}$ afirma que os grupos sociais mais expostos nunca foram passivos à presença de ameaças da natureza e que, embora seja expressiva a quantidade de estratégias de que lancem mão para enfrentá-las, essas não são reconhecidas tampouco valorizadas em termos macrossociais.

A teoria dos desastres surge em grande medida como esforço do campo disciplinar sociológico e como uma alternativa à teoria dos hazards, tratando os desastres como um tipo específico de problema social que revela as singularidades dos modos de conflito e coesão social que afloram nesse contexto de crise. Além disso, esse campo também reconhece que os desastres desvelam a estrutura social existente e, assim, tornam mais visíveis as conexões entre as injustiças sociais precedentes e os grupos mais expostos aos perigos, bem como revelam o tipo diferenciado de exposição e de medida recuperativa adotada pelo ente público ${ }^{9,10}$. Quarantelli ${ }^{11}$ enfatiza que a sobrevalorização dos estudos de detalhamento de fatores de ameaça, na busca de uma compreensão das causas de um desastre, desvia o foco sobre aquilo que se processou no interior da sociedade para levar àquele estado de coisas. Ademais, a via explicativa de cunho sociológico permite identificar as novas nuances de intolerância social e das falhas no sistema social em relação às funções sociais essenciais que foram impedidas, bem como as nuances da ação técnica onde subjazem práticas de discriminação e preconceito social que incrementam o estresse coletivo nessa crise. Em síntese, nesse approach, o desastre é considerado como uma crise social associada a um acontecimento físico devastador e a um tempo social ${ }^{12,13}$.

Oliver-Smith ${ }^{14}$ concebe os desastres a partir de uma relação, historicamente produzida, da sociedade com o ambiente, vendo-os como mutuamente constitutivos. $\mathrm{O}$ autor adverte que os valores, as normas, as crenças, as atitudes, os sistemas produtivos e as relações estabelecidas entre os grupos envolvidos são aquilo que assenta a capacidade social para lidar com o ambiente e, nele, lidar com um potencial agente destrutivo. Além disso, os desastres podem ser estudados como um aspecto dos conflitos socioambientais mais amplos onde, conforme Porto ${ }^{15}$, se desvela a complexidade do mundo social a qual envolve questões culturais e organizacionais. Apesar disso, são as racionalidades socialmente simplificadoras as que preocupantemente se difundem e se assentam no imaginário social e, desde aí, consolidam certos atores nos lugares de poder para decidir as políticas no tema.

\section{A visão institucional de defesa civil sobre desastre}

Nos estudos sobre desastres, Gilbert ${ }^{16}$ identificou três paradigmas vigentes nas últimas décadas, sendo o mais antigo deles, moldado no contexto americano da Guerra Fria, o que toma o desastre como uma espécie de guerra. Nele, o Estado adota um discurso que exige reação diante de uma agressão feita por um agente externo e o monitoramento constante desse "inimigo". Segundo o referido autor, a deliberada confusão entre guerra e desastre favoreceu os altos investi- 
mentos em sofisticados aparatos tecnológicos, a atuação de um quadro técnico regido por uma racionalidade militarizada e com poder político considerável. Esse paradigma, embora em revisão nos Estados Unidos e nos demais países desenvolvidos desde os anos de 1980 é, ainda, o dominante no Brasil. Ocorre que, sob essa influência, os desastres se tornaram crônicos neste país.

O último decênio (2004-2013) o Brasil apresentou 19.441 decretos municipais de situação de emergência (SE) ou de estado de calamidade pública (ECP), reconhecidos pela Secretaria Nacional de Defesa Civil do Ministério da Integração Nacional (Tabela 1). Tais crises se disseminam para novos municípios, mas também se repetem nos mesmos municípios, estejam eles inseridos em unidades da federação consideradas de maior desenvolvimento quanto nas de menor desenvol- vimento. Chegam a abranger, em média, $94,68 \%$ dos municípios nos cinco estados com maior frequência de desastres, com recorrência municipal média de 89,60 \% (Tabela 2).

Um aspecto dessa cronicidade é o marco conceitual e o quadro analítico adotado pelo Sistema Nacional de Proteção e Defesa Civil (SINPDEC) para enquadrar o problema e adotar soluções. O arcabouço legal de defesa civil vem se alterando no último decênio, para dar maior agilidade à movimentação financeira dos recursos públicos voltados às medidas recuperativas decorrentes de desastres, sobretudo, envolvendo a contratação de obras civis.

Porém, o conceito de desastre adotado institucionalmente permaneceu intacto desde a criação da Política Nacional de Defesa Civil, no ano de 1995, e da criação do Sistema Nacional

Tabela 1. Número de reconhecimento de SE/ECP realizados pela SEDEC/MI, período 2004-2013.

\begin{tabular}{lccc}
\hline Ano & $\begin{array}{c}\text { Número de } \\
\text { solicitações }\end{array}$ & $\begin{array}{c}\text { Número de municípios } \\
\text { solicitantes }\end{array}$ & $\begin{array}{c}\text { \% municípios solicitantes em relação } \\
\text { ao total de municípios brasileiros }\end{array}$ \\
2004 & 1.760 & 1.447 & 26,00 \\
2005 & 1.711 & 1.511 & 27,15 \\
2006 & 991 & 789 & 14,18 \\
2007 & 1.615 & 1.096 & 19,69 \\
2008 & 1.502 & 1.028 & 18,47 \\
2009 & 1.292 & 1.080 & 19,41 \\
2010 & 2.765 & 1.912 & 34,36 \\
2011 & 1.282 & 984 & 17,68 \\
2012 & 2.776 & 2.342 & 42,14 \\
2013 & 3.747 & 1.938 & 33,98 \\
& Total $=19.441$ & & Média anual $=25,31$ \\
\hline
\end{tabular}

Fonte: sistematizado a partir de informações da SEDEC/MI.

Tabela 2. Distribuição de decretos de Situação de Emergência/Estado de Calamidade Pública nas cinco Unidades da Federação (UF) com maior número de emergências no período 2004-2013 (ano-base da SEDEC/MI).

\begin{tabular}{|c|c|c|c|c|c|c|c|}
\hline \multirow[b]{2}{*}{ Ranking } & \multirow[b]{2}{*}{ UF } & \multirow[b]{2}{*}{$\begin{array}{c}\mathrm{N}^{0} \text { de decretos de } \\
\text { emergência no período }\end{array}$} & \multirow[b]{2}{*}{$\begin{array}{c}\mathrm{N}^{\circ} \text { total de } \\
\text { municípios da UF }\end{array}$} & \multicolumn{2}{|c|}{$\begin{array}{c}\text { No de municípios da } \\
\text { UF com decreto de } \\
\text { emergência }\end{array}$} & \multicolumn{2}{|c|}{$\begin{array}{c}\text { Número de } \\
\text { municípios com } \\
\text { mais de } 1 \text { decreto } \\
\text { no período }\end{array}$} \\
\hline & & & & No & $\begin{array}{l}\text { \% relativo } \\
\text { à UF }\end{array}$ & No & $\begin{array}{c}\% \text { relativo } \\
\text { à UF }\end{array}$ \\
\hline $1^{\circ}$ & RS & 2.631 & 497 & 484 & 97,38 & 463 & 93,16 \\
\hline $2^{\circ}$ & $\mathrm{SC}$ & 2.095 & 295 & 295 & 100 & 286 & 96,95 \\
\hline $3^{\circ}$ & $\mathrm{CE}$ & 1.888 & 184 & 181 & 98,37 & 178 & 96,74 \\
\hline $4^{\circ}$ & $\mathrm{PB}$ & 1.856 & 223 & 217 & 97,31 & 210 & 94,17 \\
\hline $5^{\circ}$ & BA & 1.713 & 417 & 353 & 84,65 & 311 & 74,58 \\
\hline Total & & 10.183 & 1.616 & 1.530 & 94,68 & 1.448 & 89,60 \\
\hline
\end{tabular}

Fonte: Sistematizado a partir das informações da Secretaria Nacional de Defesa Civil do Ministério da Integração Nacional, SEDEC/MI. 
de Defesa Civil (SINDEC), em 2005. A lei recente que instituiu o Sistema Nacional de Proteção e Defesa Civil, de número 12.608, publicada no Diário Oficial da União em 11 de abril de 2012, não define o que é desastre, mas remete ao decreto $\mathrm{n}^{\circ} 7.257$, de 4 de agosto de 2010, que traz a definição que já era usual: desastre é um "resultado de eventos adversos, naturais ou provocados pelo homem sobre um ecossistema vulnerável, causando danos humanos, materiais ou ambientais e consequentes prejuízos econômicos e sociais". O discurso em torno de eventos provocados pelo homem remete a um homem genérico, a-histórico, e desestimula que o imaginário social destrinche esse homem numa complexa tessitura de atores e forças que se entrechocam e que resulta, dentre outros, em que alguns tenham maior poder de interferência nas dinâmicas ecossistêmicas e no território do que os outros, que se sintam privilegiadamente protegidos das ameaças e outros mais expostos. No Artigo 13 da referida lei 12.608, destaca-se a crença na tecnociência como fator de redução de desastres, quando o governo de Dilma Rousseff autoriza a criação de um sistema de informações, devidamente informatizado, que é visto como um sistema de monitoramento de desastres. No referido documento, tal sistema visa ao compartilhamento dos dados atualizados para respaldar medidas de prevenção, mitigação, alerta, resposta e recuperação em situações de desastre em todo o território nacional; porém, trata-se tão somente do monitoramento das condições atmosféricas, hidrológicas e da estabilidade dos terrenos sujeitos aos escorregamentos de massa e afins. E, assim, desoladoramente, a análise do contexto social que engendra os processos de vulnerabilização socioambiental fica de fora da informação vista como prioritária para respaldar as estratégias de redução dos desastres.

Os desastres catastróficos ocorridos na região serrana do Rio de Janeiro, no ano de 2011, foram um dos motes deste esforço de atualização da base legal e justificaram, no Artigo 13 da referida lei, a criação do Centro Nacional de Monitoramento de Desastres Naturais (CEMADEN), nas instalações do INPE, no município de Cachoeira Paulista/SP, bem como a ampliação do quadro humano e da estrutura física do Centro Nacional de Gerenciamento de Riscos e Desastres (CENAD), vinculado à Secretaria Nacional de Defesa Civil (SEDEC). O CENAD, criado em 2005, estava instalado em uma sala de 30 metros quadrados, mas, em 2011, foi reestruturado e transferido para um espaço de 600 metros quadrados ${ }^{17}$. No primeiro, foram articuladas expertises em tempo e clima, hidrologia, geologia, cartografia, geografia física e áreas afins e, no segundo, foram congregados e/ou atuaram em parceria agentes de defesa civil, agentes de inteligência, engenheiros, geólogos, meteorologistas e outros, confirmando a preferência da gestão presidencial de Dilma por uma abordagem de hazards.

Na mesma perspectiva de agilização do trânsito de informações, porém, de empobrecimento da possibilidade de integrá-las num marco analítico social e crítico, houve um enxugamento do formulário através do qual o gestor municipal transmite ao nível federal a avaliação de danos havidos no contexto local de situação de emergência ou estado de calamidade pública. No formulário vinculado à legislação antiga, denominado Avaliação de Danos (AVADAN), havia condições de o gestor explicitar, com maior detalhamento, o panorama de danos e prejuízos envolvendo infraestruturas públicas essenciais, perdas econômicas e ambientais, danificação e destruição de moradias e o conjunto de pessoas afetadas, além da capacidade institucional local de lidar com o problema. A nova legislação (Instrução Normativa $\mathrm{n}^{\circ} 1$ de 24 de agosto de 2012) substituiu o AVADAN pelo Formulário de Informações do Desastre (FIDE), de preenchimento eletrônico e mais sintético. No FIDE, o evento causador do sinistro somente pode ser descrito segundo as restritas alternativas oferecidas pela Classificação e Codificação Brasileira de Desastres (COBRADE) - que substituiu o mais amplo Código de Desastres, Ameaças e Riscos (CODAR), vinculado à política anterior - e, de forma excludente, leva o gestor municipal a optar por desastres nas categorias naturais ou tecnológicos ao invés de permitir a conexão dos fatos e favorecer uma abordagem complexa do problema. Por exemplo, as epidemias estão enquadradas, no COBRADE, na categoria de desastres naturais. Tanto um quanto o outro formulário apresentam as informações sobre o desastre de modo fragmentado ao invés de interconectá-las para favorecer o descortinamento dos efeitos sinérgicos e devastadores sobre a vida de grupos sociais específicos no cenário devastador, em relação aos demais. Por exemplo, tais formulários impedem que se observe imediatamente que eventuais mortos, feridos e desabrigados estejam vinculados entre si, numa mesma família, numa rede primária em frangalhos; que sejam eles os moradores de residências destruídas e donos de objetos identitariamente relevantes os quais foram perdidos irremediavelmente na moradia arruinada; que tais moradias estejam situadas em 
localidades cuja infraestrutura básica foi a mais comprometida nos acontecimentos e assim por diante. A desimportância atribuída à produção e análise de informações que inter-relacionam a dimensão do corpo, da família, da rede primária, da casa e do lugar de vivência faz com que esse conjunto não influa no core da política e do conhecimento científico. Uma linha da política científica estratégica foi, no nível federal, a criação do Programa Ciência sem Fronteiras (CsF), e os desastres ali aparecem numa área assaz limitada, intitulada como Tecnologias de Prevenção e Mitigação de Desastres Naturais, que blinda essa entrada para o avanço científico das ciências humanas e sociais.

O discurso oficial, assimilado e difundido pela mídia, em torno do dia do desastre, serve para demarcar cronologicamente os acontecimentos posteriores na vida das pessoas afetadas e desatendidas como pós-desastre, o que deslegitima as suas demandas em relação às privações que passou a sofrer. A abordagem tecnicista reforça o que Acserald ${ }^{18}$ denomina como processo de vulnerabilização, isto é, a relação sociopolítica de violência que esgarça o direito do outro e, no bojo da qual, o projeto de bem-estar de parte da nação nutre-se do mal-estar provocado à parte restante.

O contexto da $2^{\text {a }}$ Conferência Nacional de Proteção e Defesa Civil ( $2^{\mathrm{a}}$ CNPDC), em ocorrência ao longo do ano de 2014, não aponta para resultados auspiciosos, apesar do tema da convocação do texto de referência, lançado oficialmente, ser o de Proteção e Defesa Civil: novos paradigmas para o Sistema Nacional. Um indício do malogro dessa tentativa de produção de uma política em bases participativas, que aparenta legitimar os recursos de voz da sociedade civil, é o fato que o mesmo governo que convoca a Conferência é aquele que, contraditoriamente, renuncia a operar o topo decisório do SINPDEC, a Secretaria Nacional de Defesa Civil (SEDEC), dentro de uma racionalidade participativa e conduzida pelo meio civil. Dos cinco secretários nacionais que passaram pela pasta desde o ano de 2003 até o início de 2014 (do início da primeira gestão Lula à finalização da gestão Dilma), houve apenas um breve período de condução da pasta por uma civil. E, após bombeiros militares e policiais militares das respectivas forças do Distrito Federal, Bahia e Pernambuco sucederem-se, seguiu-se a nomeação de um general como secretário desta pasta civil. As Forças Armadas tem tido papel destacado nos desastres catastróficos, especialmente em ações de resgate, de engenharia e de saúde e essa instituição não pode ser excluída das estratégias de redução dos desastres. Contudo, os quadros destas Forças, ao somarem-se aos dos bombeiros militares e policiais militares para direcionar os rumos institucionais, distancia a instituição, cada vez mais, da racionalidade civil. Ou seja, desvirtua a compreensão da sociedade civil de que ela apresenta condições para comandar as suas próprias instituições no tratamento de temas críticos, como os desastres.

Outro indício é o de que, contraditoriamente ao desejo de renovação de paradigma, mencionado no título do texto-base de referência da Conferência, o conteúdo do documento reitera a validade dos jargões e da interpretação e atuação tecnicista como eixo orientador do debate, isto é, nega a possibilidade de acolhimento de outras racionalidades. Uma renovação de paradigma exigiria lidar com o desafio de apontar as insuficiências do sistema e inovar a base conceitual e teórica que pauta o pensamento, as políticas e os programas institucionais, o que também suporia a alteração dos atores no domínio do campo científico. Significaria alterar radicalmente o percurso, questionar a credibilidade das teorias existentes e das práticas que lhes correspondem, fazer fervilhar o campo epistêmico - o que, no caso em tela, implicaria questionar a validade das teorias que assentam o conceito de desastres naturais - e rechaçar o tecnicismo que molda as ações no plano prático. É certo que vivemos em contexto de crise de paradigmas, conforme apontou Kuhn ${ }^{19}$, isto é, paira uma difusa incapacidade de explicação das questões pungentes da sociedade; porém, mais do que a ciência em si, prevalecem em seu nome os jogos de poder, que envolvem diferentes interesses e instituições. A visão kuhniana identifica o caráter conservador da ciência e da técnica que essa respalda assim como a relutância de ambas em acolher críticas, pois protegem e ampliam os seus investimentos humanos, de tempo e de capital realizados, estejam ou não ao abrigo de uma verdade consistente para a sociedade. O texto de referência da $2^{a}$ CNPDC desconsidera essa crise e, embora se refira à renovação, teima em oferecer como base de reflexão o êxito alcançado em planos ora em execução, como o Plano Nacional de Gestão de Risco e Respostas aos Desastres (PNGRD), com gastos milionários em recursos com monitoramentos, alertas e mapeamentos. Explicitamente, propõe ao cidadão o mesmo paradigma, o mesmo enquadramento analítico e repetindo os mesmos conceitos desgastados, como o de desastre ${ }^{20}$. O escopo estreito deste conteúdo documental 
não se atreve a trazer para a pauta quais os erros e equívocos institucionais que tornaram os desastres uma crise crônica a qual a nação não suplanta. E, por derradeiro, não consta nenhuma referência, no referido documento, ao sofrimento social multidimensional dos grupos afetados nos desastres, nenhuma problematização acerca das injustiças sociais, advertindo-se apenas o cidadão sobre a necessidade de ampliar a sua percepção de risco. Não cabe no referido documento a ideia de contradições, conflitos e desigualdades sociais tampouco a indagação fulcral: o que há de natural nos desastres? Talvez, isso signifique mais nuvens cinzentas nos horizontes da condução institucional bem como nos horizontes dos que se sentem abandonados nos desastres.

\section{O tecnicismo como deflagrador do sofrimento social multidimensional}

No Brasil, os desastres têm sido crises sociais de particular intensidade, pois fundem aquilo a que Agambem ${ }^{21}$ denomina estado de exceção e vida nua. Isso porque, por um lado, a decretação de emergência pelo gestor municipal respalda a adoção de um tipo de gestão pública excepcional, que suscita a reorientação das prioridades que foram acordadas anteriormente com os eleitores, viabiliza o fluxo mais célere de recursos públicos destinados a ações não rotineiras e sobre os quais há menor controle social local. Ademais, o contexto de emergência tem propiciado crescentemente as práticas de reorganização territorial do município, favorecendo mais as ações de expulsão de moradores empobrecidos indesejáveis, sob a alegação de que esses se encontram em área de risco, do que propriamente a priorização na reversão dos riscos que incidem nestes espaços. A leitura predominantemente objetivista do meio técnico-operacional sobre os riscos tende a descartar o exame do processo de urbanização excludente. Há valorização da elaboração cartográfica de áreas de risco e se "lê os processos sociais de ocupação dessas áreas como fruto da ignorância ou do descuido da população"22, o que suscita a formação de uma opinião pública socialmente intolerante aos grupos sociais que habitam as periferias, encostas e beiras de rios. A base legal atual exige que todas as unidades da federação e o distrito federal tenham o mapa de risco de seu território, o qual serve como uma ferramenta monológica, que inviabiliza a reivindicação da família moradora em ali permanecer quando a informação cartográfica é desfavorável a isso; silenciados por tal ferramenta, os moradores são desumanizados, passíveis a uma submissão integral a essa tecnicalidade. Contudo, há um recorte de classe subjacente a adoção da classificação da área como sendo de risco: os setores afluentes tendem a legitimar a referida classificação quando a mesma respalda a prática técnica de deslocamento compulsório dos moradores indesejáveis da localidade ao mesmo tempo em que tais setores se sentem em condições políticas de exercerem seu poder de negociação sobre a ação técnica de cartografização do risco para que os seus imóveis, que apresentam melhor padrão construtivo e em áreas com melhor infraestrutura, ainda que sob as condições hidrológicas ou geológicas não propícias, sejam poupados de uma similar avaliação técnica desfavorável.

Ilustrativamente, há o caso do município de Teresópolis, cujo desastre deflagrado no ano de 2011 desencadeou intensa ação técnica de derrubada de moradias e demais instalações (incluindo estabelecimentos públicos de ensino) e, passados três anos, as soluções definitivas de moradias para os que estão sob o apoio de auxílio-moradia, despregados de seus vínculos comunitários, alguns dos quais com parte da família falecida ou desaparecida no episódio, ainda não existem. A via principal que interliga, neste município, os bairros da Cascata do Imbuí, Posse e Campo Grande, bastante afetados na ocasião, dá bem a medida da ação técnica que se pauta pela seletividade da classe social para distinguir quem pode ficar ou não no lugar, independente da proximidade com o rio e do acentuado aclive, que são as alegações técnicas para pôr abaixo as moradias "subnormais" ou "menos requintadas". O mesmo se pode dizer em relação à resolução da questão fundiária que envolve grupos sociais tradicionais no campo, indígenas e outros.

Nos desastres, o sofrimento social dos grupos mais afetados resulta essencialmente das tensões entre as esferas privada e pública da vida social, em que prolifera toda a sorte de violências. E, ao aniquilar-se a esfera privada da vida, retira-se a liberdade essencial para a preservação da substantividade do $\operatorname{ser}^{23}$. A administração pública tem lidado com o problema através da naturalização da intrusão técnica e violação do espaço doméstico, não por coincidência, dos empobrecidos e, dentre esses, especialmente no das famílias desabrigadas. Estudos sociológicos demonstram que, nos abrigos provisórios, técnicos arbitram sobre o sistema de objetos e de ações concernentes à esfera privada, sujeitando as famílias a certos padrões de atendimento de suas necessidades vitais e a uma subordinação inconteste da estrutura de 
autoridade familiar ao comando externo ${ }^{24,25}$. A concepção de cuidado integral e de acolhimento, na qual o sujeito na sua integralidade se torna o foco principal da atenção, ainda sofre resistência das práticas profissionais de diversos setores, incluso no de saúde ${ }^{26}$. Desqualifica-se a singularidade das demandas individuais. Famílias que, sem opção de acolhimento, dirigem-se aos abrigos vivenciam constante sensação de intimidação defronte a atuação técnica de defesa civil e por uma assistência social mais burocrática, voltada mais para tarefas de múltiplos cadastramentos do que para lidar diretamente com os dramas socais que ali se desenvolvem. A degradação da esfera social se explicita, entre outros, pela desconsideração dos técnicos para com as necessidades de preservação da intimidade pessoal e familiar, pelo desrespeito aos vínculos sociais das famílias com o lugar de moradia, pela negação do valor subjacente aos laços de coesão da vizinhança, enfim, pela facilidade em desvincular as famílias e suas respectivas comunidades da sua própria história ${ }^{27}$.

O Quadro 1 apresenta alguns aspectos que compõem e se inter-relacionam no processo de sofrimento e no sentimento de desamparo dos grupos sociais mais afetados nos desastres no Brasil, e serve para dar pistas acerca das práticas técnicas desumanizantes que conduzem as ações de resposta e recuperação. A replicação desse conjunto de práticas técnicas, do norte ao sul do país, vai revelando a naturalização do racismo,

Quadro 1. Descrição dos principais elementos sociais identificadores da violência técnica contra os grupos sociais mais afetados nos desastres.

\begin{tabular}{|c|c|}
\hline Tópicos & Questões \\
\hline Falecimento de pessoa da família & $\begin{array}{l}\text { - Limitação das providências públicas de recuperação de corpos } \\
\text { - Falta de apoio oficial aos ritos de luto } \\
\text { - Ausência de apoio público para a recuperação econômica mais } \\
\text { imediata da família (no caso de se tratar de falecimento de membro } \\
\text { que era arrimo de família ou equivalente, especialmente quando } \\
\text { inserido no mercado de trabalho informal) }\end{array}$ \\
\hline $\begin{array}{l}\text { Ausência ou demora de serviço } \\
\text { especializado de resgate }\end{array}$ & $\begin{array}{l}\text { - Exercício extenuante de determinadas técnicas corporais para } \\
\text { manter-se vivo ou resgatar pessoas ou animais em perigo iminente }\end{array}$ \\
\hline $\begin{array}{l}\text { Piora da qualidade ambiental no } \\
\text { interior ou circunscrição da moradia } \\
\text { afetada ou nos abrigos provisórios }\end{array}$ & - Surgimento de enfermidades e aumento de risco de lesões \\
\hline Destruição/danificação da moradia & $\begin{array}{l}\text { - Perda da funcionalidade do espaço doméstico e de objetos do } \\
\text { mundo privado, com valor material e simbólico relevante para os } \\
\text { membros da família }\end{array}$ \\
\hline $\begin{array}{l}\text { Destruição/danificação de objetos e } \\
\text { meios de trabalho }\end{array}$ & $\begin{array}{l}\text { - Inviabilidade de retorno ao exercício pleno do trabalho e } \\
\text { comprometimento da renda familiar ou do autossustento }\end{array}$ \\
\hline $\begin{array}{l}\text { Deslocamento involuntário da família } \\
\text { para abrigo provisório ou moradia de } \\
\text { membros da sua rede primária }\end{array}$ & $\begin{array}{l}\text { - Desproteção na guarda de bens móveis que ficaram na moradia de } \\
\text { origem } \\
\text { - Relativização dos direitos territoriais da família } \\
\text { - Constrangimento, tensionamento e penalização da rede primária } \\
\text { de relações da família na demanda de acolhimento, ampliando a } \\
\text { precariedade das rotinas do grupo envolvido (falta de espaço, de } \\
\text { condições de provimento alimentar, desproteção da intimidade etc.) } \\
\text { - Imposição de regras de convivência privada por terceiros }\end{array}$ \\
\hline $\begin{array}{l}\text { Interdição de moradias e expulsão dos } \\
\text { moradores }\end{array}$ & $\begin{array}{l}\text { - Dissolução da convivência comunitária devido à dispersão da } \\
\text { vizinhança } \\
\text { - Ausência de informações e providências acerca do } \\
\text { encaminhamento das soluções habitacionais definitivas }\end{array}$ \\
\hline
\end{tabular}


isto é, dos processos de racionalização no qual as demandas do outro, em situação de desvantagem social, são tidas absurdas e a sua presença vista como insuportável, julgando-se que a índole do grupo esteja além das possibilidades de práticas reformatórias, tratando-se de gente que não tem mais jeito ${ }^{28}$. Trata-se do sofrimento devido às perdas em si-humanas, materiais, sociais e simbólicas - e o da vergonha pelas perdas havidas, decorrente ao ruidoso julgamento moral dos que assistem do lado de fora aos acontecimentos devastadores, mas dele formam e disseminam opinião, no geral, culpabilizando os afetados pelas próprias tragédias ${ }^{29}$.

É de destacar as mortes nos desastres. Para os sobreviventes, o falecimento súbito e inesperado de membros da sua rede primária num desastrepor vezes, tratando-se de perdas simultâneas com quem se mantinha vínculos afetivos e sociais variados - subtrai um importante alicerce, isto é, um aspecto constitutivo do que Giddens ${ }^{30}$ denomina como "segurança ontológica". Esse tipo de morte é constantemente representado como uma forma violenta de partir, porque implica numa involuntária perda das condições ambientais e físicas para manter-se vivo. Nesses casos, a "totalidade bio-psico-social-espiritual", tanto de quem partiu quanto de seus familiares sobreviventes, foi solapada: para quem se foi, a jornada da vida ficou inesperadamente fora de controle; para quem ficou, não se teve como produzir estratégias menos penosas de transição, como a de condução de uma eventual "boa morte" e de resolução de pendências de toda a ordem ${ }^{31}$. Nos desastres relacionados às enchentes, ocorrem vários níveis de comprometimento à saúde, desde os que se referem ao abastecimento de água potável, à proliferação de agentes infecciosos presentes na água das enchentes, à contaminação de alimentos armazenados, e, no que se refere à mortalidade, aos que derivam de afogamentos, lesões, hipotermia e outros ${ }^{32}$.

Por seu turno, a utilização do termo remoção de famílias das áreas ditas de risco faz parte do repertório discursivo de cunho racista e de violência simbólica ${ }^{33}$, que o tecnicismo instaurou para se referir a um tipo de relação dos agentes do Estado com as famílias e suas moradias nas territorialidades precárias. Tal expressão coisifica aquele que é tido como ignorante, irresponsável, desprezível, colocando-o assim sob o inteiro arbítrio do técnico, que se julga em segura distância social e psicológica para decidir sobre o destino do primeiro ${ }^{34}$. A prática de remoção torna a vida privada das famílias totalmente desprotegida, ex- posta ao olhar público - com a moradia interditada e marcada, na parede externa frontal, com um código que age como sinal estigmatizante do grupo que vive/vivia no domicílio. Nos casos em que a família é conduzida ao abrigo provisório, fica claro que as normas e rotinas da vida privada são impostas por uma estrutura de autoridade eticamente distanciada que, frequentemente, entende que os abrigados abusam da boa vontade quando reivindicam o respeito aos seus valores, às suas preferências e aos seus hábitos ou quando manifestam algum desconforto físico, moral e emocional, por se sentiram continuamente vigiados e controlados. Siena e Valencio ${ }^{35}$ analisaram o aviltamento do papel do(a) chefe do lar o qual, em abrigo provisório, é recorrentemente impedido(a) de exercer as mais comezinhas práticas de afetividade e cuidado para com os demais membros da família - como através da autonomia para produzir a própria refeição e servi-la aos seus -, o que produz riscos à coesão social do grupo.

Em alguns dos casos recentes de desastres de maior gravidade ocorridos no país, como os seis estudados por Valencio et al. ${ }^{36}$, sob os auspícios do Conselho Federal de Psicologia, constatou-se que o abandono técnico dos grupos sociais mais afetados é usual, pois as medidas de recuperação são adotadas parcialmente ou sequer chegam a se materializar. Pairava sobre as famílias e comunidades inteiras a ideia de que se tornaram refugo humano $^{37}$. Os refugados sofrem não apenas do medo da morte corpórea, mas o de ser afastado da convivência com os demais, esvaziando a possibilidade de exercitar a humanidade, isto é, temem a morte social. Porém, se indagássemos que importância o risco de morte social no contexto de desastre tem para a discussão de aprimoramento institucional, a resposta seria desalentadora.

Em relação ao tecnicismo inerente a ações de defesa civil e de outros agentes do Estado, os estudos recentes de Marchezini ${ }^{38}$ sobre o processo de reconstrução de São Luiz do Paraitinga/SP - após o estado de calamidade pública, associado ao episódio de uma grande enchente ocorrida no ano de 2010 - demonstraram que a sociedade local ficou alienada em relação às soluções adotadas pelos técnicos dos vários setores (obras civis, patrimônio histórico, habitação) e, em meio à profusão de técnicos, não havia canais para que os moradores pudessem manifestar a forma como compreendiam o problema e desejavam participar das decisões. No contexto da crise aguda, entretanto, foi a própria comunidade luziense quem adotou voluntariamente a forma 
mais eficaz de salvar vidas, através da atuação de resgate dos jovens locais que foram, desde então, chamados de anjos do rafting e, ainda, mobilizouse para resgatar os bens simbólicos que lhes eram mais preciosos em termos identitários, quais sejam, as imagens sacras que estavam na Igreja Matriz destruída pelas águas. Em estudo igualmente recente, focalizando o caso das práticas de assistência social no deslocamento de famílias, da área central da cidade para um conjunto habitacional na periferia urbana, no município de Ribeirão Preto (SP), Siena ${ }^{39}$ demonstrou o quão limitado era a visão e as ações da assistência social diante os novos percalços que se impuseram na nova territorialidade das referidas famílias, submetidas tanto à perda de acesso a muitos dos serviços públicos, dos quais antes dispunham, quanto ao controle do tráfico de drogas no novo lugar de moradia. Os casos acima indicam haver uma indiferença técnica frente à humanidade dos moradores. Atua-se de modo a se eximir de uma responsabilidade moral perante o outro ${ }^{40}$. Esses que, então, ficam nas margens decisórias do Estado, nas margens sociais e territoriais, revelam aspectos da vida que insistem em permanecer obscuras nas estruturas políticas e econômicas; contudo, esses aspectos são fundamentais na caracterização dessas estruturas ${ }^{41}$.

Por fim, tais violências vão encontrando processos de resistência. Por exemplo, através das novas formas organizativas que têm como centro o tema da justiça social e dos direitos humanos que, como assinala Porto ${ }^{42}$, não se desvincula dos problemas ambientais e suscita discussões em torno de questões éticas, morais, políticas e distributivas relacionadas, dentre outros, a certas práticas institucionais do Estado. Tais formas organizativas tentam lançar uma vocalização própria e pública. Uma ilustração disso é a manifestação pública que, aos 12 dias de janeiro de cada ano, desde o ano de 2012, os moradores de Teresópolis fazem, ao se reunirem no largo da matriz da Igreja de Santa Teresa - com o apoio da associação local de vítimas do referido desastre, denominada AVIT, e da Igreja. No coreto da praça, vocalizam o seu sentimento de abandono, a dor moral e psíquica e a revolta diante a indiferença do poder público a seus dramas vividos desde então. Outra ilustração é o da criação do Movimento Nacional dos Atingidos por Desastres (MONADES), que agregou lideranças de várias comunidades afetadas por desastres no país e iniciou uma interlocução direta na esfera federal, embora os resultados práticos ainda não sejam visíveis. Uma terceira ilustração é a da formação da Rede de Cuidados (RJ), que articulou, em especial, os profissionais da psicologia que tinham atuação local nos sete municípios envolvidos nos desastres da região serrana fluminense e priorizou o atendimento psicossocial às famílias instaladas nos abrigos provisórios. Além disso, a Rede de Cuidados (RJ) tem atuado fora do contexto de crise aguda, como através de oficinas com moradores de comunidades em áreas periféricas e da realização anual de seminários que congregam as defesas civis locais e demais técnicos municipais, além de acadêmicos e representantes governamentais, favorecendo um ambiente de diálogo entre diferentes perspectivas debruçadas sobre $o$ tema dos desastres.

\section{Para concluir}

É plausível considerar certos tipos de ameaças como naturais, mas não os desastres, uma vez que são produzidos socialmente. Os processos socioambientais que engendram, simultaneamente, a precariedade das condições de vida, da proteção social oferecida e da territorialização dos grupos sociais empobrecidos favorece a ocorrência de desastres ${ }^{43}$.

O aumento da permeabilidade do tecido institucional de defesa civil para as questões sociais que são o centro do desastre, e mesmo para com uma perspectiva sociológica sobre as questões sociais, é difícil; isso exige um embate com a cultura institucional dominante. Embora algumas das limitações institucionais da defesa civil ocorram quando há constantes mudanças no quadro de funcionários e coordenadores em função da mudança dos governos municipais, esse não é o fulcro do problema que leva ao enfraquecimento institucional. A solidez institucional, em contexto democrático, não pode depender que as mesmas pessoas, em posição decisória, ali se mantenham ad infinitum, pois convém remeter ao conceito de instituição como aquilo que permanece quando as pessoas que nela atuam circulam, vão e vem, transitam na carreira e se adaptam às suas normas. Não se espera que as instituições de Estado, em contexto de modernidade, deixem de ser inerentemente burocráticas, no sentido weberiano; mas, no caso brasileiro, a instituição de defesa civil, através do SINPDEC, tem sido capturada pelo pior dos dois mundos: pela fascinação por uma cultura autoritária, que desumaniza os que mais precisam do seu atendimento, e pelo vício da cultura patrimonialista, na qual há um balcão público onde os negócios dos desastres prosperam. 
Considerar como suficiente, ou mesmo como um avanço, a concepção de desastre que atualmente norteia o Estado brasileiro, e que respalda a estruturação dos Centros técnicos supramencionados, equivaleria a contradizer a importância central que a vocalização dos grupos afetados tem para definir uma alternativa ao tecnicismo. Uma mudança de paradigma implicaria, inicialmente, reconhecer que há assimetrias nas condições de exercício do poder decisório, como também no anteparo à produção de conhecimentos alternativos à abordagem de hazards; reconhecer que essas assimetrias têm redundando numa razão hermética e que, ao invés desta, seria preciso adotar uma razão aberta para revisar as ideias dominantes de verdade ${ }^{44}$.

O contexto político que favorece essa discussão é o de democracia substancial, que se refere ao conteúdo da forma, isto é, ao propósito do Estado de manter as principais promessas que atenda à vontade geral e ao contexto em que as partes interessadas têm possibilidades equivalentes de se envolverem diretamente na tomada de decisão ${ }^{45}$, salientando que quem vivencia a experiência de desastres é quem melhor pode defini- $\mathrm{lo}^{46}$. As políticas elaboradas com base nas demandas comunitárias devem ter em conta as formas associativas próprias do local, o seu repertório cultural e os pontos de origem de autoridade local, entre outros ${ }^{47}$.

É fato que a adoção de técnicas modernas de previsão, modelagem, monitoramento e afins produzem um repertório de informações úteis e oportunas para delimitar certos fatores de ameaça, sua dinâmica e seu alcance. Entretanto, a hipervalorização de seus lugares de verdade nas esferas deliberativas sobre desastres tem constituído um obstáculo real a uma abordagem humanista no tema; esta implicaria que o ponto de partida das práticas técnicas seria envolver-se com a complexidade social, ao invés de esquecê-la.

Quanto à desumanização das práticas de administração de abrigos temporários no país, há que se ressaltar os riscos na adoção nacional de certos modelos, transplantando-os indistintamente para vários desastres, cuja tessitura socioambiental é bastante diversa. Por exemplo, nos últimos sete anos (2009-2014), difundiu-se a prática técnica de constituição de grandes acampamentos, nos quais destina-se a cada família nuclear, independente do tamanho, uma barraca de tamanho e material padronizado. Contudo, observamos in loco que os problemas decorrentes vão desde o desconforto térmico, em níveis insuportáveis - como nos casos de União dos Palma-
res/AL (2010), Barreiros/PE (2010) e Porto Velho/RO (2014), com temperaturas elevadas que impediam o uso durante o dia - à resistência cultural das famílias em aceitar instalarem-se numa barraca, receando confundir-se identitariamente com um "sem-terra", como no caso de Ilhota/ SC (2009). Porém, há recomendações mínimas razoáveis de atendimento material às famílias em contexto de abrigos provisórios, como as do Sphere Project ${ }^{48}$.

As polarizadas condições socioeconômicas de produção do espaço no Brasil são produto do contexto histórico de injustiças sociais as quais, contudo, são recorrentemente escamoteadas. Sendo o Estado uma parte constituinte da sociedade e dos conflitos sociais que lhes são inerentes, o seu tecido institucional se deixa impregnar por formas de violência objetiva e simbólica contra os setores sociais fragilizados. Enquanto os esforços de atualização do discurso e das práticas institucionais de defesa civil não ultrapassem esse approach incitador de novos conflitos, os passos para conter as ocorrências de desastres serão estéreis. Muitos órgãos de defesa civil, estaduais e municipais, são constituídos por agentes oriundos dos quadros das polícias militares, quando não estruturada formalmente como um braço operacional dessa instituição de segurança pública, de tal modo que a crise da polícia e da defesa civil, em algum ponto, se confunde. Conforme Minayo e Adorno ${ }^{49}$, paira atualmente uma crise dos aparatos policiais. E uma das razões para isso é que a imbricação das noções de risco e de polícia ideologicamente aponta para um Estado que exerce amplo domínio sobre as pessoas e sobre as suas práticas sociais. Contudo, é uma ideologia que sofre um grande questionamento da sociedade civil organizada, mais ciente dos seus direitos de cidadania e dos limites do emprego da força física e coercitiva em várias situações. Segundo os referidos autores, a valorização da discussão em torno dos direitos humanos, das técnicas de negociação e das ações de inteligência no interior das polícias militares esbarra numa arraigada visão de eficiência ligada ao uso abusivo da força, mas, aos poucos, essa situação tem se revertido.

É de se considerar que, no tange ao tema dos riscos ambientais e dos desastres, Guivant ${ }^{50}$ já havia advertido que "os leigos tendem a ser identificados como receptores passivos de estímulos independentes" e que "estima-se que os riscos percebidos pelos leigos não necessariamente correspondem aos riscos reais, analisados e calculados pela ciência”. No entanto, a dialogicidade se impõe, ao mesmo tempo, como uma nova ética e 
uma nova prática comunicativa no tema ambiental, como em temas correlatos, porque aponta para outro tipo de sociedade, a qual, fundada nos valores da pluralidade, da democracia e do reconhecimento da diferença, refuta as dicotomias da racionalidade instrumental.

Não será a aparência de contextos participativos de produção de políticas e programas nesta área aquilo que irá capturar as genuínas vocalizações e tonalidades do sofrimento social num contexto de desastre, pois as fórmulas padronizadas de participação não adicionam caminhos para a livre expressão da pessoa humana; para lidar com as humilhações decorrentes de práticas de remoção; para priorizar os cuidados com o processo de luto e continuidade de esforços públicos de busca de entes desaparecidos; para ampliar o controle social sobre os gastos nos negócios dos desastres; para prestigiar as estratégias comunitárias de autoproteção e, enfim, para priorizar o resgate da dignidade moral e material daqueles que tudo perderam, perdem e continuam perdendo nos desastres sem fim que campeiam pelo país afora.
Embora se tenha dado destaque ao contexto de crise aguda, que merece maior compreensão e debate científico no país, reiteramos que tal crise tem profunda interface com a crise crônica que se processa. Vislumbrar essa interface amplia as possibilidades organizativas dos grupos afetados nos desastres com outros grupos de desfiliados da sociedade, que lutam em torno das questões socioambientais, da reivindicação por moradia digna, por regularização fundiária, por saúde de qualidade, enfim, para garantia de direitos ora violados. Porém, a articulação mais sólida, que tem maior força para pautar uma mudança de rumo mais perene para o propósito de redução dos desastres, é a que envolve solidariamente as demais frações da sociedade civil que se sentem de tal ou qual forma prejudicadas por um modelo de desenvolvimento questionável. A trajetória ascendente de ocorrências de desastres, alastrando-se pelo país, deixa evidências de que os temas dos desastres e do desenvolvimento são, cada vez mais, indissociáveis. 


\section{Referências}

1. Mattedi MA, Butzke IC. A relação entre o social e o natural nas abordagens de hazards e de desastres. Ambiente \& Sociedade 2001; IV(9):93-114.

2. Tierney K. From the margins to the mainstream? Disaster research at the crossroads. Annu. Rev. Sociol. 2007; 33:503-525.

3. Cardoso AL. Risco urbano e moradia: a construção social do risco em uma favela do Rio de Janeiro. Cadernos IPPUR 2006; XX(1):27-48.

4. Floriani D. Ciências em trânsito, objetos complexos: práticas e discursos socioambientais. Ambiente \& Sociedade 2006; IX(1):65-80.

5. Bobbio N. Estado, governo, sociedade; por uma teoria geral da política. Rio de Janeiro: Paz e Terra; 1987.

6. Morin E. Problemas de uma epistemologia complexa. In: Morin E, organizador. O problema epistemológico da complexidade. Sintra: Publicações Europa-América; 1990. p. 13-34.

7. Lavell A. Ciencias Sociales y Desastres Naturales en América Latina: un encuentro inconcluso. In: Maskrey A, organizador. Los desastres no son naturales. Panamá: Rede de Estudios Sociales en Prevención de Desastres en América Latina; 1993. p. 111-127.

8. García-Acosta V. Introdución. In: García-Acosta V, Audefroy JF, Briones F, organizadores. Estrategias sociales de prevención y adaptación. México: Centro de Investigaciones y Estudios Superiores em Antropologia Social; 2012. p. 11-15.

9. Perry RW. What is a disaster? In: Rodríguez H, Quarantelli EL, Dynes RR, editors. Handbook of disaster research. New York: Springer; 2007. p. 1-15.

10. Quarantelli EL, Lagadec P, Boin A. A heuristic approach to future disasters and crises: new, old, and in-between types. In: Rodríguez H, Quarantelli EL, Dynes RR, editors. Handbook of disaster research. New York: Springer; 2007. p. 16-41.

11. Quarantelli EL. Epilogue. In: Quarantelli EL, editor. What is a disaster? Perspectives on the question. New York: Routledge; 1998. p. 234-273.

12. Quarantelli EL. The Social Science Study of Disasters and Mass Communication. In: Walters L, Wilkins L, Walters T, editors. Bad Tidings: Communication and Catastrophe. New Jersey: Lawrence Erlbaum; 1989. [p. 1-19]

13. Quarantelli EL. A social science research agenda for the disasters of the $21^{\text {st }}$ century: theoretical, methodologi$\mathrm{cal}$ and empirical issues and their professional implementation. In: Perry RW, Quarantelli EL, editors. What is a disaster? New answers to old questions. Newark: International Research Committee on Disasters; 2005. p. 325-396.

14. Oliver-Smith A. Global changes and the definition of disaster. In: Quarantelli EL, editor. What is a disaster? Perspectives on the question. New York: Routledge; 1998. p. 177-194.

15. Porto MFS. Complexidade, processos de vulnerabilização e justiça ambiental: um ensaio de epistemologia política. Rev Crítica de Ciências Sociais 2011; 93(jun):31-58.

16. Gilbert C. Studying disaster: changes in the main conceptual tools. In: Quarantelli E, editor. What is a disaster? Perspectives on the question. London, New York: Routledge; 1998. p. 11-18.
17. Taddei R. Sobre a invisibilidade dos desastres na antropologia brasileira. Cadernos de Trabalho da Rede Waterlat, Série Água e Desastres. No prelo 2014.

18. Acselrad $\mathrm{H}$. As cidades e as apropriações sociais das mudanças climáticas. Cadernos IPPUR 2006; XX(1):77106.

19. Kuhn TS. A estrutura das revoluções científicas. $7^{\mathrm{a}} \mathrm{ed}$ São Paulo: Perspectiva; 2003.

20. Brasil. Ministério da Integração Nacional (MIN). Proteção e Defesa Civil: novos paradigmas pra o Sistema $\mathrm{Na}$ cional, texto de referência. Brasília: SEDEC/MIN; 2013.

21. Agambem G. Homo sacer: o poder soberano e a vida nua. Belo Horizonte: Editora da UFMG; 2004.

22. Cardoso AL. Risco urbano e moradia: a construção social do risco em uma favela do Rio de Janeiro. Cadernos IPPUR 2006; XX(1):27-48.

23. Arendt H. A condição humana. $11^{\text {a }}$ ed. Rio de Janeiro: Forense Universitária; 2010.

24. Valencio N, Darós L. Tragédia das águas em Niterói e a condição de abandono dos sobreviventes. In: Valencio N, organizador. Sociologia dos Desastres: construção, interfaces e perspectivas no Brasil. São Carlos: RiMa Editora; 2013. p. 230-255.

25. Marchezini V. Campo de abandonados: a continuidade do desastre. São Carlos: RiMa Editora; 2014.

26. Mitre SM, Andrade EIG, Cotta RMM. O acolhimento e as transformações na práxis da reabilitação: um estudo dos Centros de Referência em Reabilitação da Rede do Sistema Único de Saúde em Belo Horizonte, MG, Brasil. Cien Saude Colet 2013; 18(7):1893-1902.

27. Alexander D. Modelos de vulnerabilidade social a desastres. Rev. Crítica de Ciências Sociais 2011; 93(jun):929.

28. Bauman Z. Modernidade e Holocausto. Rio de Janeiro: Jorge Zahar Editor; 1998.

29. Valencio N. Para além do 'dia do desastre': o caso brasileiro. Curitiba: Appris; 2012. (Coleção Ciências Sociais).

30. Giddens A. As consequências da modernidade. São Paulo: Editora Unesp; 1991.

31. Menezes RA, Barbosa, PC. A construção da "boa morte" em diferentes etapas da vida: reflexões em torno do ideário paliativista para adultos e crianças. Cien Saude Colet 2013; 18(9):2653-2662.

32. Freitas CM, Ximenes EF. Enchentes e saúde pública: uma questão na literatura científica recente das causas, consequências e respostas para prevenção e mitigação. Cien Saude Colet 2012; 17(6):1601-1616.

33. Bourdieu P. O poder simbólico. Rio de Janeiro: Bertrand Brasil; 2003.

34. Bauman Z. Modernidade e Holocausto. Rio de Janeiro: Jorge Zahar Editor; 1998.

35. Siena M, Valencio N. Moradias afetadas pelas chuvas: dimensões objetivas e subjetivas dos danos pelo recorte de gênero. In: Anais do III Encontro da ANPPAS; 2006; Brasília. p. 1-14.

36. Valencio N, Siena M, Marchezini V. Abandonados nos desastres: uma análise sociológica de dimensões objetivas e simbólicas de afetação de grupos sociais desabrigados e desalojados. Brasília: Conselho Federal de Psicologia; 2011.

37. Bauman Z. Vidas desperdiçadas. Rio de Janeiro: Jorge Zahar; 2005. 
38. Marchezini V. Janeiro de 2010, São Luiz do Paraitinga/ SP: lógicas de poder, discursos e práticas em torno de um desastre [tese]. São Carlos: Universidade Federal de São Carlos; 2013.

39. Siena M. A Atenção Social nos Desastres: uma análise sociológica das diversas concepções de atendimento aos grupos sociais afetados [tese]. São Carlos: Universidade Federal de São Carlos; 2012.

40. Cohn G. Indiferença, nova forma de barbárie. In: Novaes A, organizador. Civilização e barbárie. São Paulo: Companhia das Letras; 2004. p. 81-90.

41. Das V, Poole D. El estado y sus márgenes: etnografias comparadas. Cuadernos de Antropologia Social 2008; 27:19-52.

42. Porto MFS. Complexidade, processos de vulnerabilização e justiça ambiental: um ensaio de epistemologia política. Revista Crítica de Ciências Sociais 2011; 93(jun):31-58.

43. Freitas CM, Carvalho ML, Ximenes EF, Arraes EF, Gomes JO.Vulnerabilidade socioambiental, redução de riscos de desastres e construção da resiliência: lições do terremoto no Haiti e das chuvas fortes na Região Serrana, Brasil. Cien Saude Colet 2012; 17(6):1577-1586.

44. Floriani D. Ciências em trânsito, objetos complexos: práticas e discursos socioambientais. Ambiente \& Sociedade 2006; IX(1):65-80.

45. Bobbio N. Estado, governo, sociedade; por uma teoria geral da política. Rio de Janeiro: Paz e Terra; 1987.

46. Perry RW. What is a disaster? In: Rodríguez H, Quarantelli EL, Dynes RR, editors. Handbook of disaster research. New York: Springer; 2007. p. 1-15.

47. Alexander D. Modelos de vulnerabilidade social a desastres. Rev. Crítica de Ciências Sociais 2011; 93(jun):929.

48. The Sphere Project. Humanitarian Charter and Minimum Standards in Humanitarian Response. $3^{\mathrm{a}}$ ed. Rugby: Pratical Action Publishing; 2011.

49. Minayo MCS, Adorno S. Risco e (in)segurança na missão policial. Cien Saude Colet 2013; 18(3):585-593.

50 Guivant JS. A trajetória das análises de riscos: da periferia ao centro da teoria social. Rev Brasileira de Informação Bibliográfica em Ciências Sociais 1998; 46:3-37.

Artigo apresentado em 01/06/2014

Aprovado em 05/06/2014

Versão final apresentada em 07/06/2014 